Check for updates

Cite this: Nanoscale Adv., 2019, 1, 1880

\title{
Facile synthesis of a nanoporous sea sponge architecture in a binary metal oxide
}

\author{
Avijit Biswal, ${ }^{a}$ Prasanna Panda, ${ }^{\text {bc }}$ Zhong-Tao Jiang, (D) d Bankim Tripathy ${ }^{\text {bc }}$ \\ and Manickam Minakshi (D) $* d$
}

A novel galvanostatic electrochemical technique has been employed to synthesize a cobalt-nickel mixed oxide, a binary metal oxide, via a two-step route involving electrodeposition followed by calcination. A diaphragm cell was used for the electro-deposition of the binary hydroxide at room temperature in which the electrolyte comprises a nitrate and/or sulphate bath of the corresponding metal ions at $\mathrm{pH} 4$. The electrodeposited product was calcined at $300{ }^{\circ} \mathrm{C}$ to obtain the desired oxide material. The formation of the binary metal oxide has been confirmed by X-ray diffraction analysis. The scanning electron microscopy images associated with energy dispersive analysis (EDS) suggest the formation of a nanoporous sea sponge architecture consisting of an interconnected array of nanosheets aligned perpendicular to each other. The elemental mapping analysis of the binary oxide illustrated the uniformity in the distribution of $\mathrm{Co}$ and $\mathrm{Ni}$ in the composite material. The TEM image shows that binary oxides are nanocrystalline materials. A nitrogen adsorption-desorption study supports the pore size distribution behaviour of the synthesized material. The hybrid capacitor based on the binary metal oxide cathode and activated carbon anode displayed a capacitive behaviour with a capacitance of $76 \mathrm{~F} \mathrm{~g}^{-1}$ at a current rate of $2 \mathrm{~mA}$ with $98 \%$ efficiency after 1000 cycles. Due to the unique interconnected porous network and the role of binary cations, Co-Ni oxide exhibits superior electrochemical behaviour. The synthesis of binary oxides forming various morphologies, such as hexagonal, flower-shape, and sea sponge has been discussed.

Received 17th December 2018

Accepted 4th March 2019

DOI: 10.1039/c8na00402a

rsc.li/nanoscale-advances the aim of achieving a high specific capacitance with improved rate capability and long cycle life..$^{2-7}$ Among the various transition metal oxides, nickel and cobalt oxides have made a significant contribution as electrode materials for the supercapacitor device irrespective of some of their limitations. The low conductivity and limited cycling stability are considered as major drawbacks for metal oxides or hydroxides. Nevertheless, a Co-based oxide has long been considered as a promising electrode material for its high theoretical capacity and excellent pseudocapacitive properties, while nickel oxide with a lower theoretical capacity is less expensive than its Co counterpart. Therefore, various attempts have been made to overcome the drawbacks of NiO by coupling with other transition metal oxides $^{8-12}$ and carbon-based materials ${ }^{13}$ to improve its performance. Consequently, this resulted in the significant contribution made by mixed transition metal oxides owing to their high energy density and specific capacitance. ${ }^{14-18}$ The mixed transition metal oxide can be formed either by the combination of two transition metal oxides or a transition metal oxide along with a carbon-containing material in stoichiometric or nonstoichiometric compositions. These mixed transition metal oxides are evolving as promising electrode materials for all forms of energy storage devices. ${ }^{19-21}$ The reported mixed transition metal oxides perform exceptionally well with a high 
specific capacity, exceeding those of carbon/graphite based electrode materials. This is due to the complex chemical compounds of the mixed oxides. Especially, binary transition metal oxides due to the multiple oxidation states present in their cations take part in electrochemical processes, giving better capacity and cycle life stability than monometallic transition metal oxides. ${ }^{22-24}$ Mixed transition metal oxides exhibit significantly higher electrical conductivity than monometallic transition metal oxides, as they need relatively low activation energy for electron transfer between cations. ${ }^{17,25}$ Among the range of available transition metal cations, it is worth developing metal oxides of nickel combined with cobalt to utilize the synergistic effect of both metal ions ${ }^{\mathbf{2 6}}$ resulting in high electrical conductivity to realize a high rate capability.

Various methods including sol-gel, ${ }^{27,28}$ potentiostatic electrodeposition, ${ }^{17,29}$ the hydrothermal method, ${ }^{22,30}$ and coprecipitation $^{26,31}$ have been reported for the synthesis of $\mathrm{Co}-\mathrm{Ni}$ binary oxides. However, galvanostatic electrodeposition methods are more versatile owing to the simplicity of the process and possibility of tailoring the material to the need. However, a study on the synthesis of nanomaterials using galvanostatic electrodeposition has not been widely reported. The electrochemical method is an eco-friendly, cost-effective novel method as the deposition process can be tweaked through the applied current as compared to the previously reported methods. Additionally, the galvanostatic electrochemical deposition produces nanostructured particles with controlled characteristics, namely, the particle size, crystallographic orientation, mass, thickness, and morphology by adjusting the operating conditions and bath chemistry. ${ }^{32}$ A high surface area of the desired product can be obtained by calcining the electrodeposited porous binary metal hydroxide materials. Such a type of binary metal oxide has been synthesized and examined for energy storage viability.

A hybrid capacitor comprising a binary transition metal oxide as a battery-type faradaic electrode coupled with activated carbon as a capacitor-type electrode to bridge the gap between rechargeable batteries and supercapacitors has been reported here with enhanced energy density. Electrode materials with a porous architecture facilitate easy electron transport for faradaic reactions at the electrode-electrolyte interface leading to high energy density for SCs. ${ }^{33}$ Hence, the material properties of the synthesized product provide sufficient electroactive sites to play a crucial role in supercapacitor cell performance.

In this work, electrolytic production of Co-Ni binary oxides from aqueous solutions of two sets of electrolytes containing nitrate and sulphate in a two-compartment diaphragm cell (see Scheme 1) has been carried out using a novel galvanostatic electrodeposition at room temperature with subsequent calcination at $300{ }^{\circ} \mathrm{C}$. Very little work appears to have been done on the electrodeposition of binary metal hydroxides followed by calcination to obtain binary metal oxides having various morphologies. The porous architecture of highly pure Ni-Co binary oxides with a hierarchical sea sponge-like morphology is obtained by this facile two-step method. The morphologies of the material are observed to vary from hexagonal to flower shaped and then to a sea sponge architecture while varying the

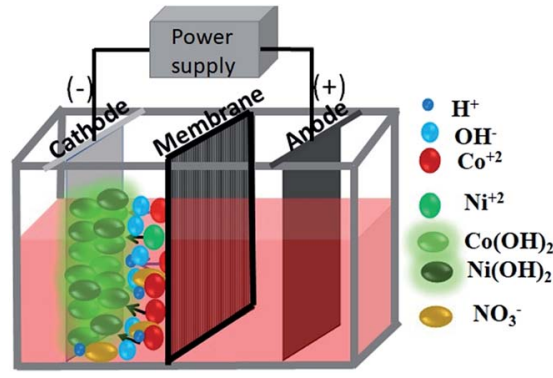

Scheme 1 Schematic diagram of the galvanostatic electrodeposition using a diaphragm cell.

electrolytic bath. The obtained materials were tested as electrodes for supercapacitors ensuring that features like fast charge and discharge rates, and high cycling stability have been met as a primary pre-requisite.

\section{Experimental}

\subsection{Preparation of metal hydroxides and binary metal oxides} by electrodeposition

All the chemicals used in this study were of pure analytical grade and were used as received without any further purification. A two-compartment diaphragm cell (shown in Scheme 1) was used for the electrodeposition process. A current was supplied from a constant current DC source (Aplab rectifier) in galvanostatic mode. Pure cobalt hydroxides and/or mixed Co-Ni hydroxides were deposited from two sets of an electrolyte containing nitrate and sulphate aqueous salt solution. Deposition of cobalt hydroxide and mixed Co-Ni hydroxides was carried out from nitrate medium containing $30 \mathrm{~g} \mathrm{dm}{ }^{-3} \mathrm{Co}\left(\mathrm{NO}_{3}\right)_{2} \cdot 7 \mathrm{H}_{2} \mathrm{O}$ and $30 \mathrm{~g} \mathrm{dm}^{-3} \mathrm{Co}\left(\mathrm{NO}_{3}\right)_{2} \cdot 7 \mathrm{H}_{2} \mathrm{O}+30 \mathrm{~g} \mathrm{dm}^{-3} \mathrm{Ni}\left(\mathrm{NO}_{3}\right)_{2}$ respectively. A sulphate bath composed of $30 \mathrm{~g} \mathrm{dm}^{-3} \mathrm{CoSO}_{4} \cdot 7 \mathrm{H}_{2} \mathrm{O}+10 \mathrm{~g} \mathrm{dm}^{-3}$ $\mathrm{NaNO}_{3}$ was used for cobalt hydroxide deposition. $\mathrm{NaNO}_{3}$ was used as the supporting electrolyte in sulphate medium.

The cathodic reduction of $\mathrm{Co}^{2+}$ to $\mathrm{Co}(\mathrm{OH})_{2}$ and/or $\mathrm{Ni}^{2+}$ to $\mathrm{Ni}(\mathrm{OH})_{2}$ was carried out on a stainless steel (SS) cathode placed in parallel to an iridium oxide coated titanium $\left(\mathrm{IrO}_{2}-\mathrm{Ti}\right)$ anode at a cathodic current density of $200 \mathrm{~A} \mathrm{~m}^{-2}$. All experiments were carried out at room temperature for $2 \mathrm{~h}$. The electrodeposited materials were removed from the cathode after the deposition and washed thoroughly with deionized water before drying in an oven. Subsequently, the resultant product was finally dried and cooled in a desiccator and subjected to physical tests such as X-ray diffraction (XRD) and other microscopy analyses.

\subsection{Calcination step and sample labelling}

Monometallic and binary hydroxides were calcined at $300{ }^{\circ} \mathrm{C}$ to convert them to their respective oxides. Then the materials were subjected to physical and electrochemical characterization. Cobalt hydroxide samples prepared from a nitrate and sulphate bath were labeled $\mathrm{CH}$-nitrate and $\mathrm{CH}$-sulphate respectively. Similarly, Co-Ni mixed hydroxides deposited from a nitrate bath were labeled $\mathrm{CNH}$-nitrate. After calcination, these samples 
were labeled CO-nitrate, CO-sulphate, and CNO-nitrate, respectively.

\subsection{Materials characterization}

Various physicochemical characterization techniques were carried out to identify the phase, surface morphology and porous nature of the prepared monometallic oxides and mixed oxides. Phase analysis was carried out using a Phillips powder diffractometer (PAN ANALYTICAL PW 1830) using Cu K $\alpha$ radiation. Nitrogen adsorption-desorption studies were carried out using a Micromeritics Tristar II surface area and porosity analyser. Before analysing, the samples were degassed at $100{ }^{\circ} \mathrm{C}$ overnight. The surface morphology of the samples was determined using field emission scanning electron microscopy (FESEM, ZEISS SUPRA 55) together with energy dispersive analysis. High-resolution transmission electron microscopy images and selected area diffraction patterns of the binary metal oxide were obtained using a JEOL JEM 2100 operated at $200 \mathrm{kV}$.

\subsection{Electrochemical characterization}

For electrochemical measurements, the electrode was prepared by mixing the active material (metal oxide), carbon black and polyvinylidene fluoride (PVDF) in a $75: 15: 10 \mathrm{wt} \%$ ratio. All ingredients were mixed in $N$-methyl-2-pyrrolidone (NMP, 250 $\mu \mathrm{L})$ to make a slurry which was coated on a small piece of graphite sheet with a coating area of $1 \mathrm{~cm}^{2}$. The coated electrode was then dried on a hot plate (at $40{ }^{\circ} \mathrm{C}$ for an hour) to evaporate the solvent before any electrochemical testing.

The electrochemical behaviour of metal oxide materials was investigated by cyclic voltammetry and impedance spectroscopy using an SP-150, Bio-Logic instrument and galvanostatic charge-discharge and rate capability measurements were carried out by using a Battery Analyser (MTI corp, USA) operated using a battery testing system (BTS). Electrochemical behaviour of both monometallic and binary metal oxides was investigated by using three-electrode cells with $2 \mathrm{M} \mathrm{NaOH}$ as the electrolyte and $\mathrm{Pt}$ wire and $\mathrm{Hg} / \mathrm{HgO}$ as the counter and reference electrodes, respectively, over a potential range from $0.0-0.6 \mathrm{~V}$ at different sweep rates. Galvanostatic charge/discharge curves in the potential range of $0.2-1.6 \mathrm{~V}$ at various current densities were recorded. Electrochemical impedance spectroscopy (EIS) was carried out with an amplitude of $5 \mathrm{mV}$ over a frequency range of $10 \mathrm{MHz}$ to $700 \mathrm{kHz}$ at an open circuit potential. The specific capacitance (SC) and energy density $(E)$ of the device were calculated using the following equations:

$$
\begin{gathered}
\mathrm{SC}\left(\mathrm{F} \mathrm{g}^{-1}\right)=I \Delta t / m \Delta V \\
E\left(\mathrm{~W} \mathrm{~h} \mathrm{~kg}^{-1}\right)=E=1 / 2 \mathrm{SC} \Delta V^{2}
\end{gathered}
$$

where SC is the specific capacitance $\left(\mathrm{F} \mathrm{g}^{-1}\right), I$ is the current (A) imposed on the cell for charge/discharge, $\Delta t$ is the time taken to discharge in seconds (calculated from the discharge curves), $m$ is the weight of the active electrode (CO-nitrate, CO-sulphate, and CNO-nitrate) in grams, and $\Delta V$ is the voltage window (V).
For a hybrid cell, in order to maintain the charge conservation between the two electrodes, the mass ratio was calculated using eqn (3)

$$
m^{+} / m^{-}=\left(\mathrm{SC}^{-} \times \Delta V^{-}\right) /\left(\mathrm{SC}^{+} \times \Delta V^{+}\right)
$$

where $m$ represents the mass in $\mathrm{g}$. $\mathrm{SC}^{-}$and $\mathrm{SC}^{+}$represent the specific capacitance for the AC and metal oxides, respectively (calculated from eqn (1)); $\Delta V^{-}$and $\Delta V^{+}$represent the discharge/ charge potential range for the $\mathrm{AC}$ and $\mathrm{CO}$-nitrate, $\mathrm{CO}$-sulphate, and CNO-nitrate electrodes, respectively.

\section{Results and discussion}

\subsection{Electrodeposition}

During the electrolysis of $\mathrm{Co}\left(\mathrm{NO}_{3}\right)_{2}$ solution, nitrate ions from the bath play a vital role in the deposition of cobalt hydroxide. ${ }^{34}$ Initially, on applying a potential to the electrochemical diaphragm cell, nitrate ions get reduced to nitrite and hydroxyl ions are formed. The process during reduction is given as:

$$
\mathrm{NO}_{3}{ }^{-}+\mathrm{H}_{2} \mathrm{O}+2 \mathrm{e}^{-} \rightarrow \mathrm{NO}_{2}^{-}+2 \mathrm{OH}^{-} \text {(aq.) }
$$

Hydroxyl groups formed via electrochemical reduction are expected to react with $\mathrm{Co}^{2+}$ ions present in the electrolyte. As a result, cobalt hydroxide is deposited on the substrate according to the following reaction:

$$
\mathrm{Co}^{2+}+2 \mathrm{OH}^{-} \rightarrow \mathrm{Co}(\mathrm{OH})_{2}
$$

Nickel is also deposited in a similar manner

$$
\mathrm{Ni}^{2+}+2 \mathrm{OH}^{-} \rightarrow \mathrm{Ni}(\mathrm{OH})_{2}
$$

3.1.1 Effect of the electrolyte on the current efficiency (CE) and energy consumption (EC). Apart from the cobalt nitrate electrolyte, sulphate and chloride baths need a supporting electrolyte, $\mathrm{NaNO}_{3}$ to generate nitrate ions, which will assist the formation of cobalt hydroxides. As shown in Table 1, about 98\% current efficiency was achieved for the deposition of cobalt hydroxide from a bath of aq. cobalt nitrate solution. However, $100 \%$ CE resulted in both cases of cobalt sulphate and cobalt chloride aq. solution. However, there is a decrease in energy consumption when deposition is varied from the nitrate to chloride bath. But the chloride bath leads to the formation of

Table 1 Effect of the electrolyte on CE and EC

\begin{tabular}{lll}
\hline & $\begin{array}{l}\text { Current } \\
\text { efficiency } \\
(\mathrm{CE})(\%)\end{array}$ & $\begin{array}{l}\text { Energy } \\
\text { consumption } \\
(\mathrm{EC})\left(\mathrm{kW} \mathrm{h} \mathrm{kg}^{-1}\right)\end{array}$ \\
\hline $30 \mathrm{~g} \mathrm{dm}^{-3} \mathrm{Co}^{\left.-\mathrm{NO}_{3}\right)_{2}}$ & 98 & 2.24 \\
$30 \mathrm{~g} \mathrm{dm}^{-3} \mathrm{CoSO}_{4}$ & 100 & 2.20 \\
$+10 \mathrm{~g} \mathrm{dm}^{-3} \mathrm{NaNO}_{3}$ & & \\
$30 \mathrm{~g} \mathrm{~L}^{-1} \mathrm{CoCl}_{2}$ & 100 & 2.11 \\
$+10 \mathrm{~g} \mathrm{~L}^{-1} \mathrm{NaNO}_{3}$ & &
\end{tabular}


toxic chlorine gas at the anode, which results in the corrosion of the electrode. Hence nitrate and sulphate baths were chosen as a suitable bath in this study for cobalt hydroxide synthesis.

3.1.2 Effect of supporting electrolyte $\mathrm{NaNO}_{3}$. As cobalt hydroxide deposition was not feasible from the sulphate bath in the absence of nitrate ions, a supporting electrolyte, sodium nitrate was chosen. Its concentration was varied ranging from 5 , 10 and $20 \mathrm{~g} \mathrm{dm}^{-3}$. The results (in Table 2) revealed that with an increase in sodium nitrate concentration from 5 to $10 \mathrm{~g} \mathrm{dm}^{-3}$ the $\mathrm{CE}$ increases from 86 to $100 \%$, which then remains constant even for a higher amount of $20 \mathrm{~g} \mathrm{dm}^{-3}$ sodium nitrate solution. Interestingly, the energy consumption value was found to be minimum in the presence of $10 \mathrm{~g} \mathrm{dm}^{-3}$ of sodium nitrate. Hence, the experiments carried out using the sulphate bath have used $10 \mathrm{~g} \mathrm{dm}^{-3}$ sodium nitrate as the supporting electrolyte in this study.

3.1.3 Effect of the binary electrolyte. Basically, as our aim is to synthesize cobalt-nickel binary hydroxide, electrolytic baths containing nickel nitrate and nickel sulphate along with cobalt nitrate and cobalt sulphate were chosen. The result (in Table 3)

Table 2 Effect of the supporting electrolyte concentration on CE and EC

\begin{tabular}{lll}
\hline Electrolyte & $\begin{array}{l}\text { Current } \\
\text { efficiency } \\
(\mathrm{CE})(\%)\end{array}$ & $\begin{array}{l}\text { Energy } \\
\text { consumption } \\
(\mathrm{EC})\left(\mathrm{kW} \mathrm{h} \mathrm{kg}^{-1}\right)\end{array}$ \\
\hline $30 \mathrm{~g} \mathrm{dm}^{-3} \mathrm{CoSO}_{4}+5 \mathrm{~g} \mathrm{dm}^{-3} \mathrm{NaNO}_{3}$ & 86 & 2.86 \\
$30 \mathrm{~g} \mathrm{dm}^{-3} \mathrm{CoSO}_{4}+10 \mathrm{~g} \mathrm{dm}^{-3} \mathrm{NaNO}_{3}$ & 100 & 2.20 \\
$30 \mathrm{~g} \mathrm{dm}^{-3} \mathrm{CoSO}_{4}+20 \mathrm{~g} \mathrm{dm}^{-3} \mathrm{NaNO}_{3}$ & 100 & 2.22
\end{tabular}

Table 3 Effect of the binary electrolyte on CE and EC

\begin{tabular}{lll}
\hline Electrolyte & $\begin{array}{l}\text { Current } \\
\text { efficiency } \\
(\mathrm{CE})(\%)\end{array}$ & $\begin{array}{l}\text { Energy } \\
\text { consumption } \\
(\mathrm{EC})\left(\mathrm{kW} \mathrm{h} \mathrm{kg}^{-1}\right)\end{array}$ \\
\hline $\begin{array}{l}30 \mathrm{~g} \mathrm{dm}^{-3} \mathrm{Co}\left(\mathrm{NO}_{3}\right)_{2} \\
+30 \mathrm{~g} \mathrm{dm}^{-3} \mathrm{Ni}_{\left(\mathrm{NO}_{3}\right)_{2}}\end{array}$ & 100 & 1.99 \\
$30 \mathrm{~g} \mathrm{dm}^{-3} \mathrm{CoSO}_{4}+30 \mathrm{~g} \mathrm{dm}^{-3}$ & 100 & 1.96 \\
$\mathrm{NiSO}_{4}+10 \mathrm{~g} \mathrm{dm}^{-3} \mathrm{NaNO}_{3}$ & &
\end{tabular}

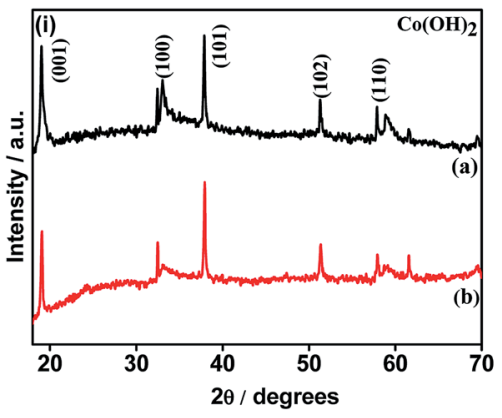

revealed that the sulphate bath leads to consumption of less energy than the nitrate bath with about $100 \%$ current efficiency in both the cases. This may be due to the presence of the supporting electrolyte which increases the conductance of the solution resulting in a decrease in voltage of the deposition process. However, in this work, we have investigated the mixed cobalt-nickel oxide deposited from the nitrate bath only.

\subsection{Structural analysis of metal hydroxides and binary metal oxides}

The X-ray diffraction patterns of the electrodeposited samples and subsequent to calcination are shown in Fig. 1 and 2, respectively. The cobalt hydroxides deposited from nitrate and sulphate baths prior to calcination ( $\mathrm{CH}$-nitrate, $\mathrm{CH}$-sulphate) shown in Fig. 1i have diffraction peaks at $2 \theta$ values with the respective ( $h k l$ ) indices, 19.00 (001), 33.080 (100), 37.89 (101), 51.34 (102), and 57.92 (110) without any second phase as an impurity. This indicates that the electrodeposited product in both the cases of an electrolytic bath (such as nitrate and sulphate) can be well indexed to a pure phase of $\mathrm{Co}(\mathrm{OH})_{2}$ having a hexagonal crystal structure (JCPDS card no. 30-0443). Fig. 1(ii) shows the X-ray diffraction pattern of the electrodeposited material from a bath containing cobalt nitrate and nickel nitrate mixed solution prior to calcination. The XRD pattern revealed the formation of mixed phases of $\mathrm{Co}(\mathrm{OH})_{2}$ and $\mathrm{Ni}(\mathrm{OH})_{2}$ with the hexagonal crystal structure (JCPDS card no. 30-0443, 74-2075) indicating that the binary metal hydroxides have been formed as expected in the presence of two electrolytes.

XRD analysis of the cobalt hydroxides (CO-nitrate, COsulphate) after calcination was carried out and the results are shown in Fig. 2(i) a and b. The XRD pattern revealed the formation of cubic cobalt oxide $\left(\mathrm{Co}_{3} \mathrm{O}_{4}\right)$ (JCPDS card no. 761802 ) for both the samples. The diffraction peaks at angles $(2 \theta)$ of about 19.175, 31.225, 36.775, 44.725 and 59.425 are assigned to the (111), (220), (311), (102) and (110) planes of the $\mathrm{Co}_{3} \mathrm{O}_{4}$ crystal lattice, respectively. Fig. 2(ii) shows the X-ray diffraction pattern of binary cobalt-nickel oxide (CNO-nitrate) with diffraction peaks of $19.185,31.245,36.776,44.375$ and 59.442 (JCPDS card no. 76-1802) corresponding to the $\mathrm{Co}_{3} \mathrm{O}_{4}$ crystal lattice. However diffraction peaks at about 36.975, 43.375, 72.075 and at 30.825 and 64.775 correspond to the different planes of $\mathrm{NiO}$ and $\mathrm{Ni}_{2} \mathrm{O}_{3}$ crystal lattices (JCPDS card no. 471049) respectively. These results suggest the fact that the binary

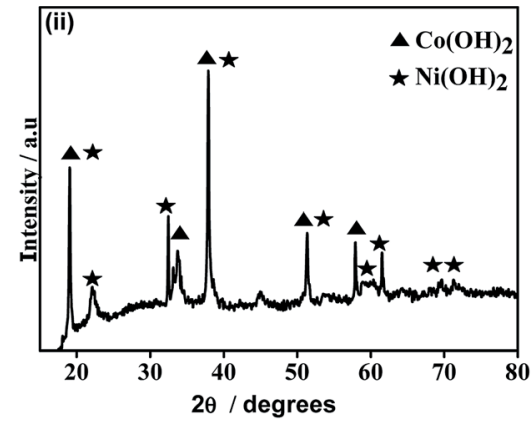

Fig. 1 X-ray diffraction pattern of (i-a) $\mathrm{CH}$-nitrate, (i-b) $\mathrm{CH}$-sulphate, and (ii) $\mathrm{CNH}$-nitrate. 

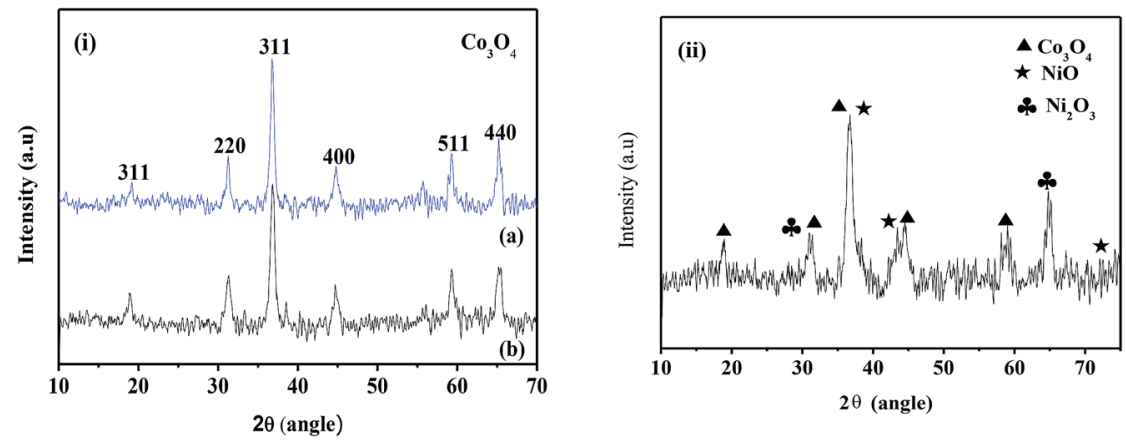

Fig. 2 X-ray diffraction pattern of (i-a) CO-nitrate, (i-b) CO-sulphate, and (ii) CNO-nitrate.

oxide materials contain the phases of $\mathrm{Co}_{3} \mathrm{O}_{4}$ along with different phases of nickel such as $\mathrm{NiO}$ and $\mathrm{Ni}_{2} \mathrm{O}_{3}$. The mean crystallite size $(L)$ of the CNO-nitrate sample was calculated using the Debye-Scherrer equation (eqn (7)) and found to be $23.40 \mathrm{~nm}$.

$$
L=K \lambda /(\beta \cos \theta)
$$

where $K$ is the particle shape dependent factor $(\sim 0.94$ for spherical particles with cubic symmetry), $\theta$ is the angle of the diffraction peak, $\beta$ is the full width at half maximum, and $\lambda$ is the wavelength of the X-ray $(\lambda=0.15406 \mathrm{~nm})$.

\subsection{FE-SEM and TEM analyses: hexagonal, flower-shape, and sea sponge morphologies}

The microstructures and the surface morphologies of the cobalt oxides (CO-nitrate and CO-sulphate) and cobalt-nickel mixed oxide (CNO-nitrate) samples are shown in Fig. 3. Fig. 3 shows the typical SEM images of metal oxides and the observed significant difference in the morphology during the electrodeposition process. The results revealed that the CO-nitrate sample shows hexagonal plate-like crystals with a maximum size of $1 \mu \mathrm{m}$ along with various smaller hexagonal plate-like crystallites within the nanosize range.

Fig. $3 \mathrm{~b}$ shows the SEM image of the CO-sulphate sample with quite different morphological changes indicating a flower-like porous structure. The SEM images of binary metal oxides under different magnifications, shown in Fig. 3c and d, exhibit a sea sponge-like architecture highly porous in nature. On a close view, it was observed that each spongy architecture is composed of nanoplate like crystallites with a fairly uniform thickness, giving highly porous texture to the crystal. Thus, an interconnected porous network may lead to a high surface area resulting in an excellent performance for electrochemical
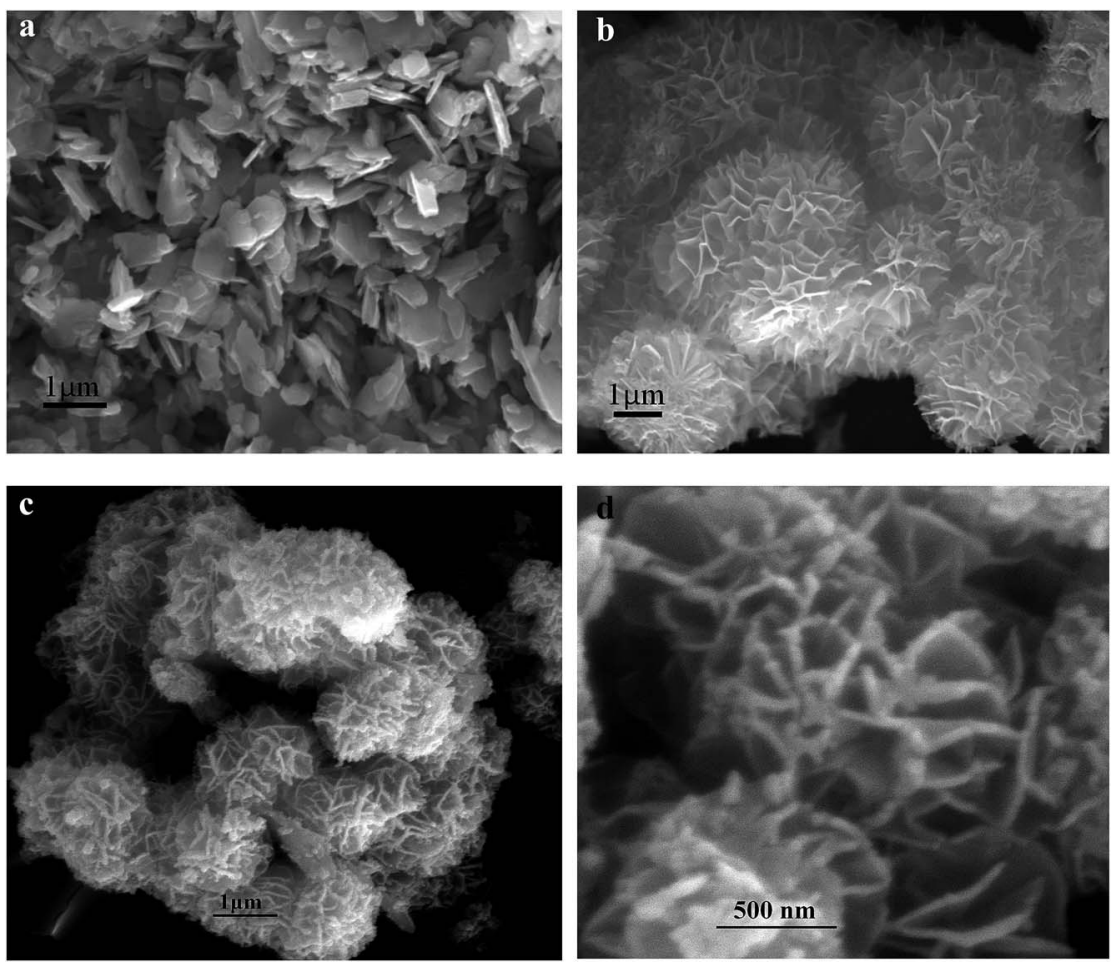

Fig. 3 FE-SEM images of (a) CO-nitrate, (b) $\mathrm{CO}$-sulphate, and $\mathrm{CNO}$-nitrate samples at (c) lower and (d) higher magnifications. 


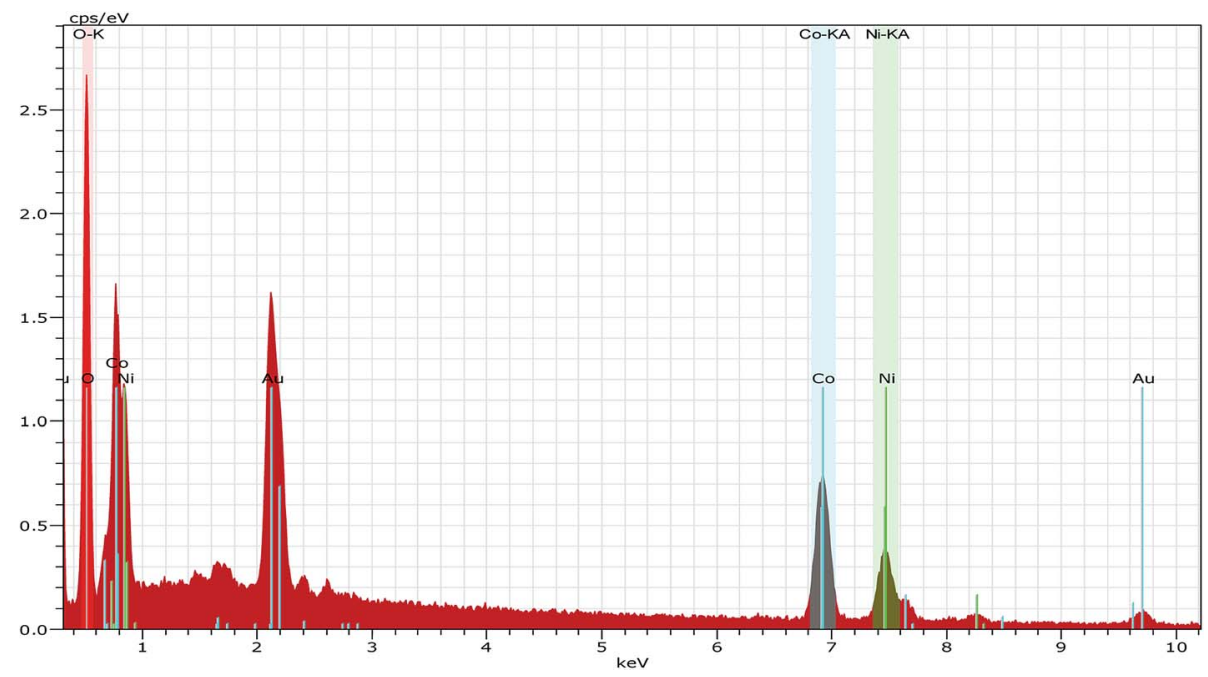

Fig. 4 Energy dispersive analysis spectra (EDS) of the CNO-nitrate sample.

applications due to easy ionic/electronic transport. ${ }^{35}$ Fig. 4 shows the corresponding energy dispersive analysis of the CNO-nitrate sample. The relative intensities of the EDS spectra showed that the mixed oxide material consists of an approximately equal metal molar ratio of cobalt to nickel ions in the crystal lattice. The elemental mapping analysis of the CNOnitrate sample is illustrated in Fig. 5 and the area of the analysed region is shown in the FE-SEM image. It is clearly seen that the two elements $\mathrm{Co}$ and $\mathrm{Ni}$ have been distributed uniformly on each crystal along with oxygen. Generally, the brighter the colour, the higher is the elemental concentration of $\mathrm{Ni}$ and Co. The unique structure of the resultant binary oxide with the homogeneity of the metal atom distribution aids the increase of the specific capacitance and energy density.

The transmission electron microscopy (TEM) images of the binary metal oxide (CNO-nitrate) are shown in Fig. 6. The bright field images at different magnifications (Fig. 6a and b) show individual particles with a crystallite size in the range 10-25 nm, which is consistent with the values of the XRD data obtained using Scherrer's formula. Fig. 6c shows striations illustrating the nanocrystallinity of the binary oxide material. The corresponding selected area diffraction pattern (SADP in Fig. 6d) is not a representative of the whole material, however, it shows bright spots in the diffraction rings confirming the crystallinity. The $d$-values obtained from the SADP pattern are in accordance with the results of the X-ray diffraction.
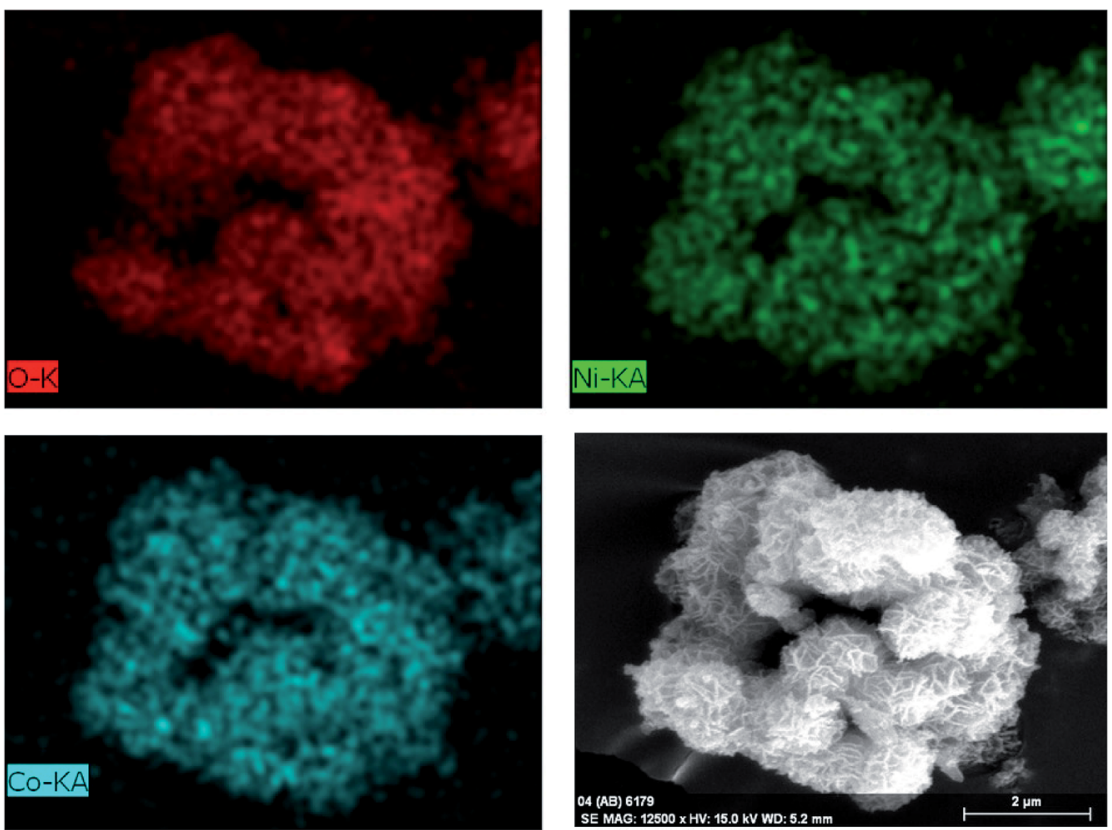

Fig. 5 EDS elemental mapping of $\mathrm{O}, \mathrm{Ni}$, and $\mathrm{Co}$ in the $\mathrm{CNO}$-nitrate sample, their concentration is correlated with the intensity of the red, green and cyan colours. The area of the sample used for EDS analysis is shown in the respective FE-SEM image. 

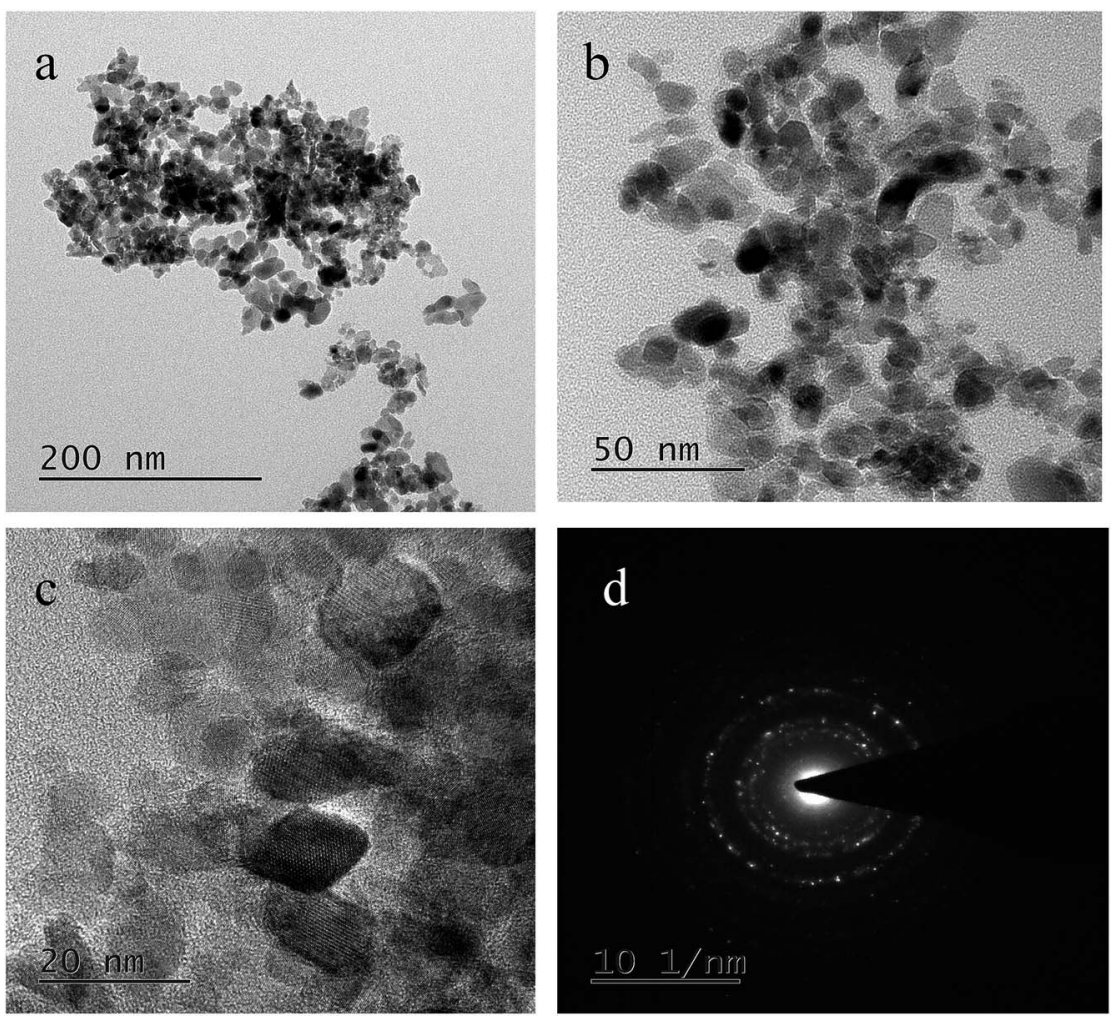

Fig. 6 Transmission electron microscopy (TEM) images of the CNO-nitrate sample $(a-c)$ at different magnifications and (d) the corresponding selected area diffraction pattern (SADP).

\subsection{Pore-size analysis}

To examine the pore size distribution of the metal oxides, nitrogen gas-sorption measurement was performed for COnitrate, CO-sulphate, and CNO-nitrate samples. Fig. 7 shows the nitrogen adsorption-desorption isotherms and the corresponding Barrett-Joyner-Halenda (BJH) pore-size distribution curves of CO-nitrate, $\mathrm{CO}$-sulphate, and CNO-nitrate samples. The $\mathrm{N}_{2}$ physisorption isotherms of all the samples show a typeIV isotherm with an $\mathrm{H}_{2}$-type hysteresis loop indicating the mesoporous nature of the materials. ${ }^{36}$ Cobalt-nickel mixed oxide i.e. CNO-nitrate showed a shift in the loop to a higher relative pressure approaching $P / P_{0}=0.99$, signifying the fact that a large number of mesopores are present compared to that of the pure cobalt oxide samples (CO-nitrate, CO-sulphate) and hence the higher surface area of $62 \mathrm{~m}^{2} \mathrm{~g}^{-1}$.

The BJH pore-size distribution curve showed a significant difference between the CNO-nitrate, CO-nitrate and COsulphate samples. CO-nitrate and $\mathrm{CO}$-sulphate showed a poresize distribution curve centered at about $8.63 \mathrm{~nm}$; however, the pore-size distribution curve shifted to a higher pore volume and centered at about $9.31 \mathrm{~nm}$ for the CNO-nitrate sample, suggesting that a larger pore size is required for easy transfer of the electrolyte through the mixed oxide material matrix. Based on the above results, CNO-nitrate may correspond to an excellent candidate, as the mesopores reduce the diffusion distance for electrolyte ion transport while enhancing the adsorption of ions during the electrochemical energy storage. ${ }^{2,35}$

\subsection{Electrochemical characterisation}

3.5.1 Three-electrode configuration. To examine and distinguish the electrochemical behaviour of CO-nitrate, $\mathrm{CO}-$ sulphate, and CNO-nitrate, all of the materials were evaluated in a $2 \mathrm{M} \mathrm{NaOH}$ aqueous electrolyte using a standard three-electrode system (details are provided in Section 2.4). The potentiostatic (Fig. 8a-c) and galvanostatic (Fig. 8d-f) measurements of the as-prepared electrodes were carried out in a potential window of $0.6 \mathrm{~V} v s . \mathrm{Hg} / \mathrm{HgO}$. The typical cyclic voltammetric (CV) curves are shown in Fig. 8a-c. While a reduction peak (C1) has been observed for all the electrodes a well-defined reduction peak (C1) followed by an oxidation peak (A1) is more prominent for CNO-nitrate, binary metal oxide. However, the shape of the $\mathrm{CV}$ curves is comparable to that for the nitrate electrodes studied (Fig. 8a and c) but the curve for sulphate (Fig. 8b) is illdefined. The electrochemical behaviour of CO-nitrate and COsulphate exhibits a quasi-reversible faradaic process, which is associated with the electron transfer in the $\mathrm{Co}^{2+/ 3+}$ redox couple involving the ability of $\mathrm{OH}^{-}$to be inserted/extracted into/from the $\mathrm{Co}_{3} \mathrm{O}_{4}$ electrodes. ${ }^{1,37}$ The extent of the electrochemical reaction is being more for sulphate resulting in a discharge capacitance of $100 \mathrm{~F} \mathrm{~g}^{-1}$ and less for monometallic nitrate resulting in $60 \mathrm{~F} \mathrm{~g}^{-1}$. As shown in the $\mathrm{CV}$ curves, at higher sweep rates, the specific current increases indicating the fast kinetics and low internal resistance of the electrodeposited electrodes. It has to be noted that (Fig. 8c) the separation between C1 (shift of $0.1 \mathrm{~V}$ towards more positive) and A1 (shift of $0.1 \mathrm{~V}$ towards more 

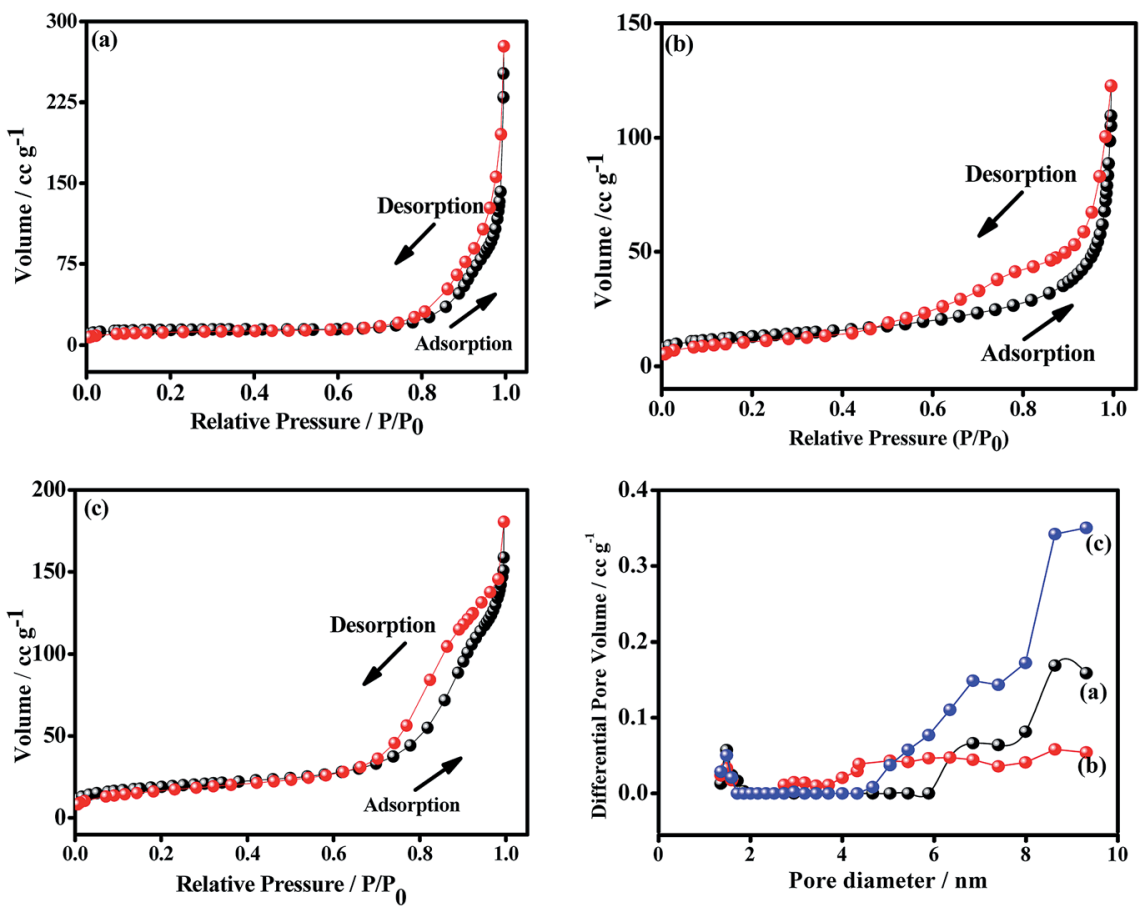

Fig. 7 Nitrogen adsorption-desorption and pore-size distribution plots of (a) CO-nitrate, (b) CO-sulphate, and (c) CNO-nitrate samples.

negative) gradually widens when the scan rate increased to 5 and $10 \mathrm{mV} \mathrm{s}^{-1}$; this is attributed to a decrease in the utilization of the active material caused by limited diffusion of ions from
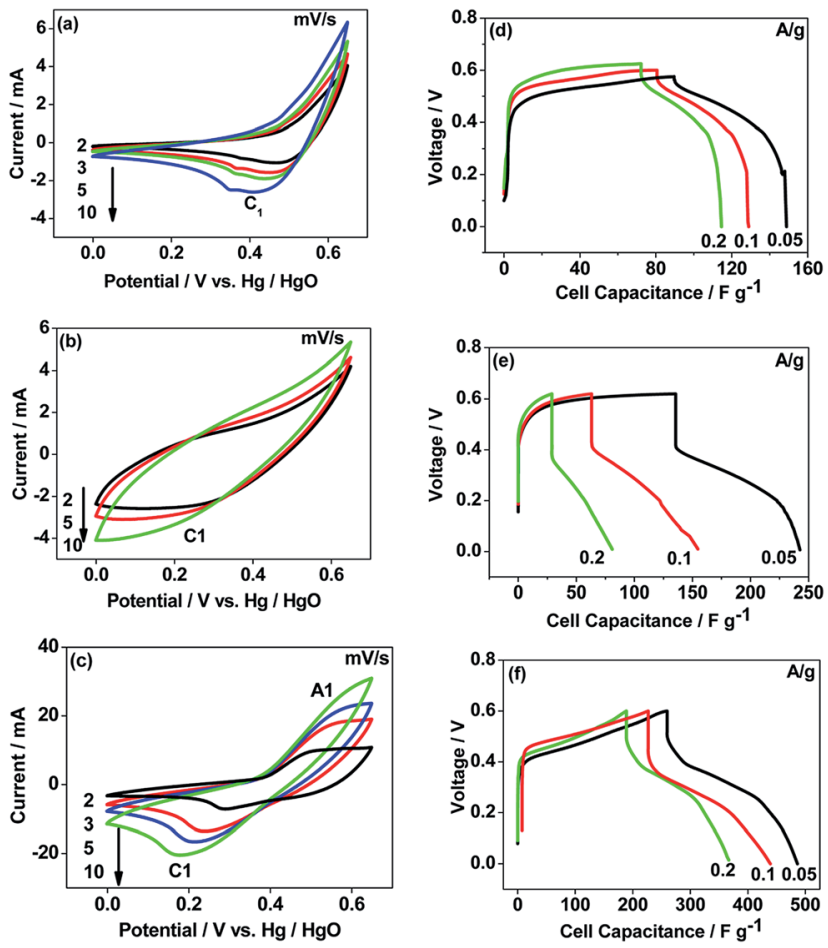

Fig. 8 (a-c) First cyclic voltammetric (CV) curves, and (d-f) first charge-discharge behaviour of $\mathrm{CO}$-nitrate, $\mathrm{CO}$-sulphate, and $\mathrm{CNO}$ nitrate electrodes, respectively in a three-electrode configuration. Sweep rates $\left(\mathrm{mV} \mathrm{s}^{-1}\right)$ and current rates $\left(\mathrm{A} \mathrm{g}^{-1}\right)$ are shown in respective figures. the electrolyte ${ }^{35}$ into the binary metal oxide material. The integrated area of the binary metal oxide (Fig. 8c) is much larger than those for CO-nitrate and CO-sulphate (Fig. 8a and b) implying the larger specific capacitance that the material can deliver. This is justified in the corresponding galvanostatic charge-discharge curve implying a discharge capacitance of 250 $\mathrm{F}^{-1}$. This suggests that both $\mathrm{Ni}$ and Co contribute to the electrochemical process and to both faradaic and non-faradaic reactions. Nonetheless, the $\mathrm{Co}^{2+/ 3+}$ and $\mathrm{Ni}^{2+/ 3+}$ redox couples are so close that it is difficult to distinguish them in the CV curve (Fig. 8c).$^{38}$ To further study the specific capacitance and the rate capability, galvanostatic measurements were carried out and charge-discharge curves of CO-nitrate, CO-sulphate, and CNOnitrate are shown in Fig. 8d-f at different current rates in the respective plots. The curves for nitrates (Fig. 8d, f) are almost symmetrical with a negligible IR drop, suggesting the rapid current-voltage response of the nitrates in the electrolytic bath during electrodeposition. However, the available discharge capacitance of $250 \mathrm{~F} \mathrm{~g}^{-1}$ is higher for binary metal oxide (CNO) nitrates (Fig. 8f) which is four times higher than that of COnitrate (in Fig. 8d). The nearly symmetric charge-discharge curves imply the high coulombic efficiency and low polarization of CO-nitrates and CNO-nitrates, while in the case of sulphate, the shape of the charge-discharge curves in Fig. 8e is distorted with distinct polarization, supported by the ill-defined CV curve in Fig. 8b.

3.5.2 Two-electrode configuration (hybrid device). To further evaluate CO-nitrate, CO-sulphate, and CNO-nitrate for practical applications, a hybrid device has been fabricated with a battery (redox) type monometallic oxide or binary metallic oxide materials as the cathode coupled with a capacitor type activated carbon as the negative electrode in $2 \mathrm{M} \mathrm{NaOH}$ 
electrolyte (details are provided in Section 2.4). The mass of both the electrodes has been balanced to achieve the maximum specific capacitance. Typical cyclic voltammetric (Fig. 9a-c) and charge-discharge (Fig. 9d-f) measurements of the hybrid devices were carried out in the potential window of $1.6 \mathrm{~V} v s$. activated carbon. The CV curves indicate both faradaic and nonfaradaic regions (pseudocapacitive in nature) contributing to the total capacitance of the device. The hybrid structure has merged the merits of the two active components and the electrochemical performance of the binary metal oxide (Fig. 9c) shows a specific capacitance of $76 \mathrm{~F} \mathrm{~g}^{-1}$ with good rate performance and excellent electrochemical stability. Among the three materials, CO-nitrate, CO-sulphate, and CNO-nitrate, the binary metal oxide in Fig. 9c is superior in terms of possessing a typical capacitor-like shape, ${ }^{1}$ with no obvious redox peaks, and a near symmetric current response on reversing the potential back to the initial point. The corresponding charge-discharge curves are shown in Fig. 9d-f. The binary metal oxide shows symmetric charge and discharge curves with no obvious inflections at higher current densities, while CO-nitrate and CO-sulphate showed a distorted triangular profile (deviated from the capacitive behaviour) arising from the sharp ohmic resistance of the cell ${ }^{39}$ (see Table 4). The specific discharge capacitances based on the total mass of the two electrodes are calculated to be 15,23 , and $76 \mathrm{~F} \mathrm{~g}^{-1}$ for the samples CO-nitrate, CO-sulphate, and CNO-nitrate (Fig. 9d-f), respectively, at a current rate of 0.05 $\mathrm{A} \mathrm{g}^{-1}$. It can be seen that the available discharge capacitance of binary metallic oxide is much higher than that of monometallic oxide, which is well consistent with the CV results (in Fig. 9a-c). This is due to the rational material design of the sea-sponge architecture and thus outstanding performances are revealed due to the synergistic effect of Co and Ni cations. Fig. 9f also displays the rate capability of CNO-nitrate at the current rates from 0.05 to $0.5 \mathrm{~A} \mathrm{~g}^{-1}$. The obtained discharge capacitances are calculated to be 76, 73, 57 and $53 \mathrm{~F} \mathrm{~g}^{-1}$ at a current rate of 0.05 , $0.1,0.2$ and $0.5 \mathrm{~A} \mathrm{~g}^{-1}$, respectively. Interestingly, $75 \%$ of the available capacitance was retained even at a high current rate of $0.5 \mathrm{~A} \mathrm{~g}^{-1}$. However, when the current rate (Fig. 10c) was
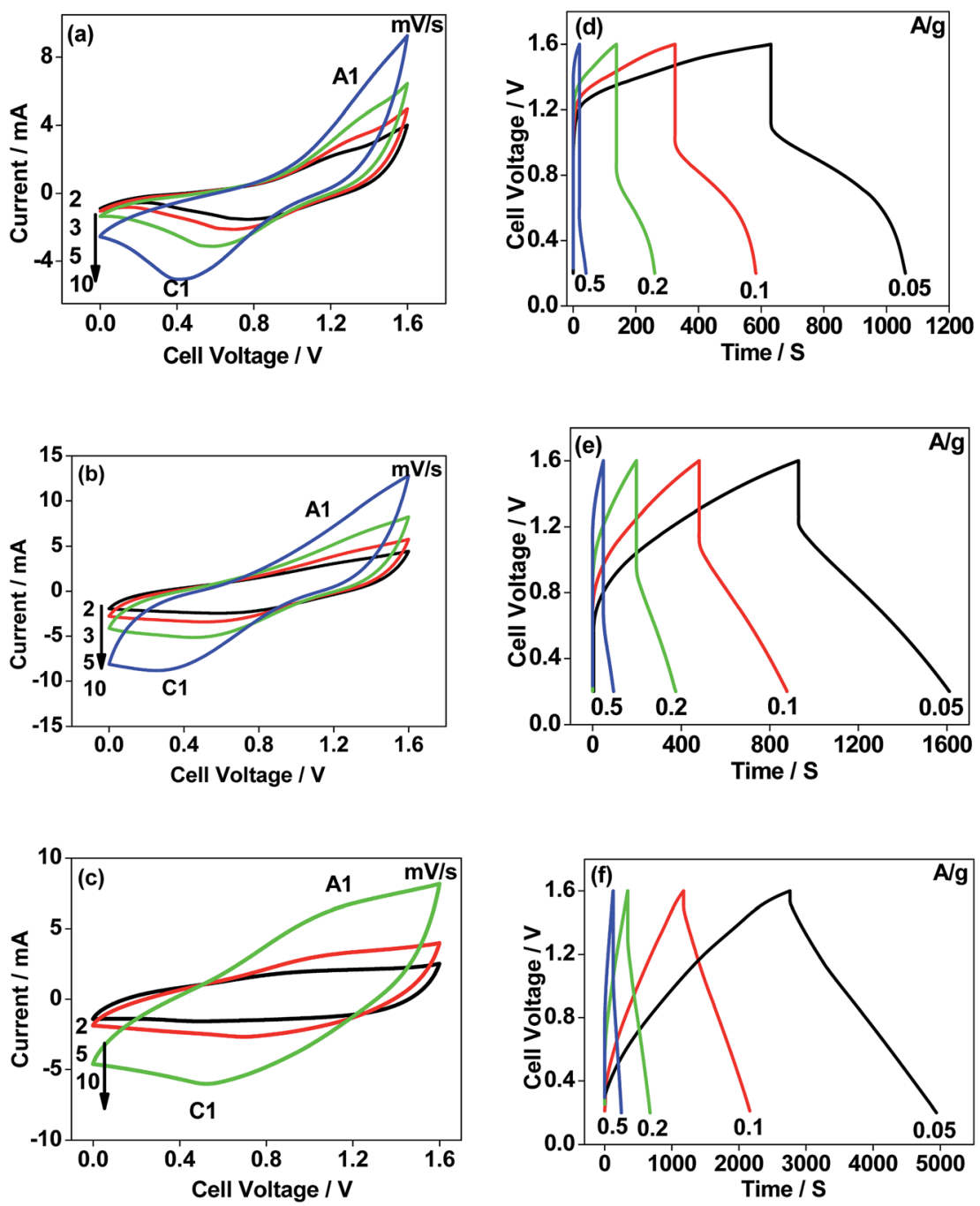

Fig. 9 Hybrid cell (two-electrode configuration) of metal oxides as the positive electrode and activated carbon as the negative electrode in $2 \mathrm{M}$ $\mathrm{NaOH}$ electrolyte. First cyclic voltammetric (CV) curves (a-c), and first charge-discharge behaviour (d-f) of CO-nitrate, CO-sulphate, and CNOnitrate electrodes, respectively in a supercapacitor. Both CV and charge-discharge curves show pseudocapacitive behaviour. 
Table 4 The equivalent circuit parameters deduced by fitting the impedance plots to the circuit shown in Fig. 11

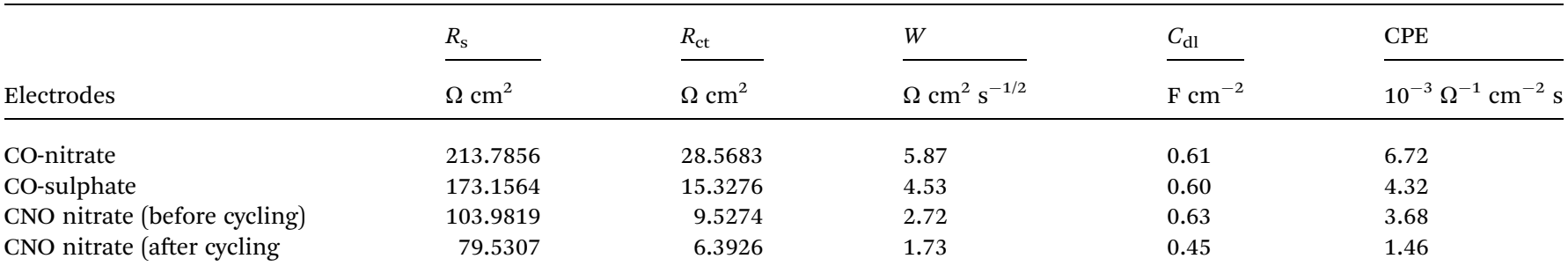

increased from $0.5 \mathrm{~A} \mathrm{~g}^{-1}$ to $2 \mathrm{~A} \mathrm{~g}^{-1}$, the available specific capacitance is reduced to $25 \mathrm{~F} \mathrm{~g}^{-1}$ indicating the good rate capability of CNO nitrate. On the other hand, at a higher current rate of $2 \mathrm{~A} \mathrm{~g}^{-1}$, CO-nitrate and CO-sulphate (in Fig. 10a and b) exhibited a capacitance as low as $15 \mathrm{~F} \mathrm{~g}^{-1}$ and $10 \mathrm{~F} \mathrm{~g}^{-1}$, respectively, which could be due to the absence of nickel in the composite.

The CNO nitrate hybrid capacitor (shown in Fig. 9f) delivers a specific capacitance of $76 \mathrm{~F} \mathrm{~g}^{-1}$ with an energy density of $75 \mathrm{~W}$ $\mathrm{h} \mathrm{kg}^{-1}$ at a power density of $125 \mathrm{~W} \mathrm{~kg}^{-1}$. The electrochemical performance of the binary metal oxide reported in this work compares well with similar materials reported in the literature like $\mathrm{Co}_{3} \mathrm{O}_{4}\left(57 \mathrm{~F} \mathrm{~g}^{-1}\right),{ }^{40} \mathrm{NiCo}_{2} \mathrm{O}_{4}\left(64 \mathrm{~F} \mathrm{~g} \mathrm{~g}^{-1}\right),{ }^{33} \mathrm{Co}-\mathrm{Ni}$ oxides $(82 \mathrm{~F}$ $\left.\mathrm{g}^{-1}\right),{ }^{1} \mathrm{CoMoO}_{4}\left(25 \mathrm{~F} \mathrm{~g}^{-1}\right),{ }^{41} \mathrm{NiMoO}_{4}\left(100 \mathrm{~F} \mathrm{~g}^{-1}\right),{ }^{42}$ and other ternary metal oxides. ${ }^{43}$ Furthermore, the device constructed using the binary metal oxide exhibited long-term stability, reproducing a similar linear charge-discharge curve after 1000 cycles (Fig. 11a) which is a typical requirement for a hybrid capacitor suitable for any practical applications. The cycling stability test conducted by means of repeated charge-discharge over 1000 cycles at a current density of $0.1 \mathrm{~A} \mathrm{~g}^{-1}$ revealed (Fig. 11b) excellent stability with a capacitance retention of $98 \%$. During the initial ten cycles, the discharge capacitance was low $\left(60 \mathrm{~F} \mathrm{~g}^{-1}\right)$ and then the capacitance was increased to $76 \mathrm{~F} \mathrm{~g}^{-1}$ during 100 cycles and then stabilized thereon. This could be attributed to the activation of mesopores occurring after a few cycles to provide an accessible area for charge accommodation. This is further confirmed by the Nyquist plots (in Fig. 11c) that compare the electrodes before and after cycling. The equivalent circuit for the Nyquist plots is shown in Fig. 12 and the fitting values are presented in Table 4. Both the plots (in Fig. 11c) were composed of a distorted semicircle in the high-frequency region and a linear part in the low-frequency region, illustrating a typical capacitive type behaviour. This is described by the parallel circuit of $R_{\mathrm{ct}}$ (charge-transfer resistance) and $C_{\mathrm{dl}}$ (double layer capacitance) while $C_{\mathrm{p}}$ (pseudo capacitance) is for the steep inclined line, which is replaced by a constant phase element (CPE) while including the chemical properties of the metal oxides. The chemical diffusion impedance is referred to as the Warburg impedance $(W) \cdot{ }^{44}$ In both the high frequency
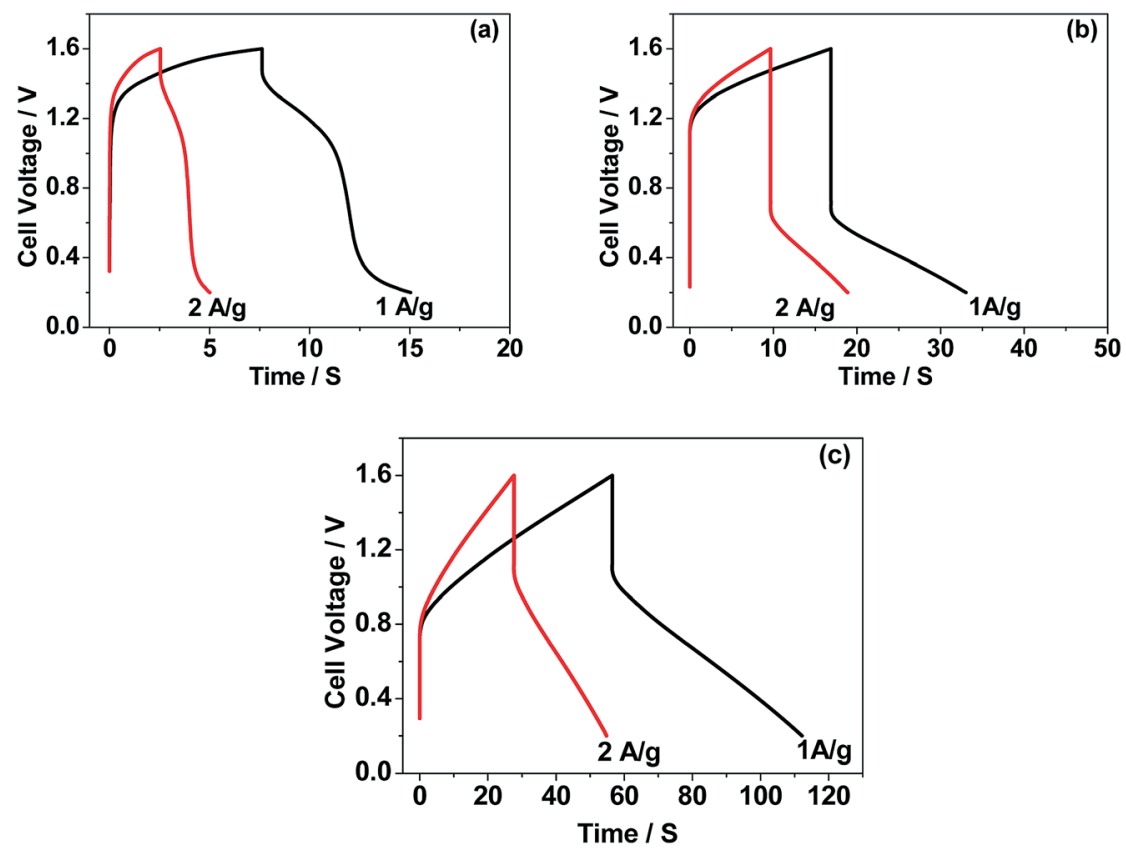

Fig. 10 Hybrid cell (two-electrode configuration) of metal oxides as the positive electrode and activated carbon as the negative electrode in $2 \mathrm{M}$ $\mathrm{NaOH}$ electrolyte. Charge-discharge profiles at higher current rates $1 \mathrm{~A} \mathrm{~g}^{-1}$ and $2 \mathrm{~A} \mathrm{~g} \mathrm{~g}^{-1}$ for (a) CO-nitrate, (b) CO-sulphate, and (c) CNO-nitrate electrodes, respectively. 

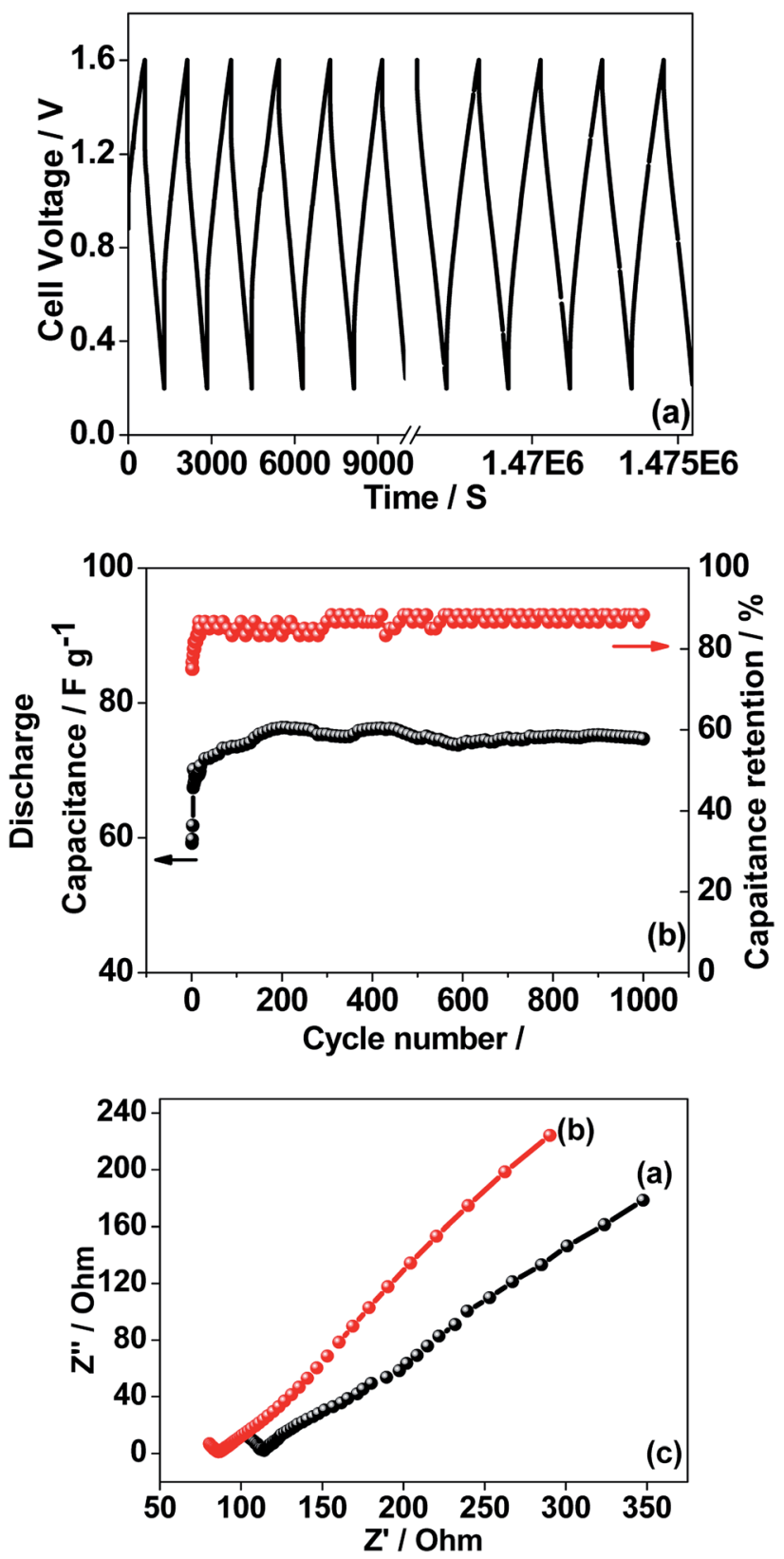

Fig. 11 (a) Multiple charge-discharge curves of the supercapacitor comprising $\mathrm{AC} \| \mathrm{CNO}$ nitrate (binary metal oxide) in $2 \mathrm{M} \mathrm{NaOH}$ electrolyte, (b) cycling stability at a current rate of $0.1 \mathrm{~A} \mathrm{~g}^{-1}$ showing the capacitance retention and coulombic efficiency, and (c) Nyquist plot comparing the impedance in the high frequency region and capacitive behaviour in the low frequency region for the hybrid cell before and after cycling.

and low frequency areas, the cycled CNO nitrate electrode exhibited low $R_{\mathrm{s}}$ (solution resistance of $79.53 \Omega \mathrm{cm}^{2}$ ) and $R_{\mathrm{ct}}$ (diameter of the semicircle, $6.39 \Omega \mathrm{cm}^{2}$ ) values (tabulated in Table 4), indicating the lower ion diffusion resistance due to the nanoporous network (as illustrated in the TEM images, Fig. 6) for the binary metallic oxides with a sea-sponge architecture. The slope line at the low-frequency region for the cycled electrode is steeper implying the capacitive like behaviour ascribed to the low mass transfer resistivity of the electrolyte ${ }^{3}$ within the nanoporous

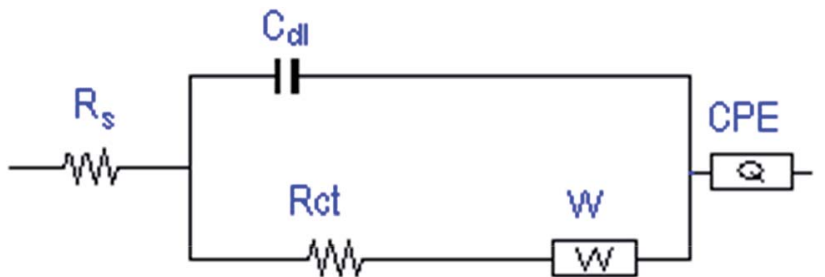

Fig. 12 The equivalent circuit of the supercapacitor comprising $A C \| C N O$ nitrate (binary metal oxide) in $2 \mathrm{M} \mathrm{NaOH}$ electrolyte. The term $R_{\mathrm{s}}$ denotes solution resistance, $R_{\mathrm{ct}}$ refers to charge transfer resistance, $C_{\mathrm{dl}}$ refers to double layer capacitance, $W$ refers to Warburg impedance, and CPE refers to constant phase element.

structure of CNO nitrate. In the case of CO-nitrate and COsulphate electrodes, the intrinsic resistance of the electrode $\left(R_{\mathrm{s}}\right)$ and kinetic resistance $\left(R_{\mathrm{ct}}\right.$ and $\left.\mathrm{CPE}\right)$ to ion transfer at the interface between the metal oxide surface and electrolyte are relatively higher (see Table 4) than those for CNO nitrate. Therefore, the surface electrochemical reaction $\left(R_{\mathrm{s}}, R_{\mathrm{ct}}\right)$, formation of the double layer at the interface $\left(C_{\mathrm{dl}}\right)$, and sequential electron transfer from the surface to the bulk (W and CPE) all appear to be favourable for the CNO nitrate electrode which confirms the experimental values of higher discharge specific capacitance.

\section{Conclusions}

Facile synthesis of a sea sponge architecture in the binary metal oxide, Co-Ni mixed oxide, is achieved by electrodeposition using a diaphragm cell comprising a nitrate and sulphate bath with a $\mathrm{pH}$ of 4 followed by calcination. A maximum current efficiency of $100 \%$ was obtained from the galvanostatic electrodeposition. After calcination, monometallic and binary metal oxide electrodes showed various morphologies and the bath chemistry played a crucial role in determining the overall capacitive behaviours. The morphology and pore size distribution of the obtained metal oxides could easily be tweaked with the operating conditions. The electrochemical tests demonstrate that CNO nitrate exhibits superior characteristics with a specific discharge capacitance of $250 \mathrm{~F} \mathrm{~g} \mathrm{~g}^{-1}$ (three-electrode configuration) and $76 \mathrm{~F} \mathrm{~g} \mathrm{~g}^{-1}$ (two-electrode configuration) and excellent rate capability delivering an energy density of $75 \mathrm{Wh}$ $\mathrm{kg}^{-1}$ at a power density of $125 \mathrm{~W} \mathrm{~kg}^{-1}$, with long-term cyclability of $98 \%$ retention of its initial capacitance. The results establish that the hybrid capacitor using CNO nitrate as the positive electrode and activated carbon as the negative electrode can work at $1.6 \mathrm{~V}$ and is a potential candidate for supercapacitor applications.

\section{Conflicts of interest}

There are no conflicts to declare.

\section{Acknowledgements}

One of the authors $(\mathrm{AB})$ would like to acknowledge the grant body, Technical Education Quality Improvement Program 
(TEQIP - III), Department of Higher Education, Government of India for funding this work.

\section{References}

1 J. Zhang, F. Liu, J. P. Cheng and X. B. Zhang, Binary Nickelcobalt Oxides Electrode Materials for High-performance Supercapacitors: Influence of its Composition and Porous Nature, ACS Appl. Mater. Interfaces, 2015, 7, 17630-17640.

2 D. Dong, Y. Liu and J. Li, $\mathrm{Co}_{3} \mathrm{O}_{4}$ hollow polyhedrons as bifunctional electrocatalysts for reduction and evolution reactions of oxygen, Part. Part. Syst. Charact., 2016, 33, 887-895.

3 G. Wang, L. Zhang and J. Zhang, A Review of Electrode Materials for Electrochemical Supercapacitors, Chem. Soc. Rev., 2012, 41, 797-828.

4 H. Chen, L. Hu, Y. Yan, R. Che, M. Chen and L. Wu, One-Step Fabrication of Ultrathin Porous Nickel HydroxideManganese Dioxide Hybrid Nanosheets for Supercapacitor Electrodes with Excellent Capacitive Performance, $A d v$. Energy Mater., 2013, 3, 1636-1646.

5 C. Maria Magdalene, K. Kaviyarasu, J. Judith Vijaya, B. Siddhardha, B. Jeyaraj, J. Kennedy and M. Maaza, Evolution on the heterostructured $\mathrm{CeO}_{2} / \mathrm{Y}_{2} \mathrm{O}_{3}$ binary metal oxide nanocomposites for UV/Vis light induced photocatalytic degradation of Rhodamine - B dye for textile engineering application, J. Alloys Compd., 2017, 727, 1324-1337.

6 A. Mobeen Amanulla, S. K. Jasmine Shahna, R. Sundaram, C. Maria Magdalane, K. Kaviyarasu, D. Letsholathebe, S. B. Mohamed, J. Kennedy and M. Maaza, Antibacterial, magnetic, optical and humidity sensor studies of $\beta$ $\mathrm{CoMoO}_{4}-\mathrm{Co}_{3} \mathrm{O}_{4}$ nanocomposites and its synthesis and characterization, J. Photochem. Photobiol., B, 2018, 183, 233-241.

7 H. Chen, S. Zhou and L. Wu, Porous Nickel HydroxideManganese Dioxide-Reduced Graphene Oxide Ternary Hybrid Spheres as Excellent Supercapacitor Electrode Materials, ACS Appl. Mater. Interfaces, 2014, 6, 8621-8630.

8 J. Liu, J. Jiang, M. Bosman and H. J. Fan, Three-Dimensional Tubular Arrays of $\mathrm{MnO}_{2}-\mathrm{NiO}$ Nanoflakes with High Areal Pseudocapacitance, J. Mater. Chem., 2012, 22, 2419-2426.

9 N. Padmanathan and S. Selladurai, Electrochemical Capacitance of Porous NiO- $\mathrm{CeO}_{2}$ Binary Oxide Synthesized via Sol-Gel Technique for Supercapacitor, Ionics, 2014, 20, 409-420.

10 J.-H. Kim, K. Zhu, Y. Yan, C. L. Perkins and A. J. Frank, Microstructure and Pseudocapacitive Properties of Electrodes Constructed of Oriented $\mathrm{NiO}^{-\mathrm{TiO}_{2}}$ Nanotube Arrays, Nano Lett., 2010, 10, 4099-4104.

11 M. C. Liu, L. B. Kong, C. Lu, C. Li, X. M. Li, Y. C. Luo and L. Kang, A Sol-Gel Process for Fabrication of $\mathrm{NiO} / \mathrm{NiCo}_{2} \mathrm{O}_{4} /$ $\mathrm{Co}_{3} \mathrm{O}_{4}$ Composite with Improved Electrochemical Behaviour for Electrochemical Capacitors, ACS Appl. Mater. Interfaces, 2012, 4, 4631-4636.

12 J.-H. Yang, Y. Qingtao, Y. Li, L. Mao and D. Ma, Batch Fabrication of Mesoporous Boron-Doped Nickel Oxide
Nanoflowers for Electrochemical Capacitors, Mater. Res. Bull., 2014, 59, 382-386.

13 X. X. Tu, Y. Mai, R. Chen, X. Wang, C. Gu and X. Zhao, Graphene Sheet/Porous NiO Hybrid Film for Supercapacitor Applications, Chem.-Eur. J., 2011, 17, 10898-10905.

14 C. Yuan, H. B. Wu, Y. Xie and X. W. Lou, Mixed TransitionMetal Oxides: Design, Synthesis, and Energy-Related Applications, Angew. Chem., Int. Ed., 2014, 53, 1488-1504.

15 Y. Zhang, Y. Liu, J. Chen, Q. Guo, T. Wang and H. Pang, Cobalt Vanadium Oxide Thin Nanoplates: Primary Electrochemical Capacitor Application, Sci. Rep., 2014, 4, 5687.

16 M.-T. Lee, J.-K. Chang, W.-T. Tsai and C.-K. Lin, In situ X-ray Absorption Spectroscopic Studies of Anodically Deposited Binary Mn-Fe Mixed Oxides with Relevance to Pseudocapacitance, J. Power Sources, 2008, 178, 476-482.

17 X. Lu, X. Huang, S. Xie, T. Zhai, C. Wang, P. Zhang, M. Yu, W. Li, C. Liang and Y. Tong, Controllable Synthesis of Porous Nickel-Cobalt Oxide Nanosheets for Supercapacitors, J. Mater. Chem., 2012, 22, 13357-13364.

18 J. Gomez, E. E. Kalu, R. Nelson, M. H. Weatherspoon and J. P. Zheng, Binder-Free Co-Mn Composite Oxide for Li-Air Battery Electrode, J. Mater. Chem. A, 2013, 1, 3287-3294.

19 L. Zhou, D. Zhao and X. W. Lou, Double-shelled $\mathrm{CoMn}_{2} \mathrm{O}_{4}$ Hollow Microcubes as High-Capacity Anodes for LithiumIon Batteries, Adv. Mater., 2012, 24, 745-748.

20 T.-Y. Wei, C.-H. Chen, H.-C. Chien, S.-Y. Lu and C.-C. Hu, A Cost-Effective Supercapacitor Material of Ultrahigh Specific Capacitances: Spinel Nickel Cobaltite Aerogels from an Epoxide-Driven Sol-Gel Process, Adv. Mater., 2010, 22, 347351.

21 G. Zhang, L. Yu, H. B. Wu, H. E. Hoster and X. W. Lou, Formation of $\mathrm{ZnMn}_{2} \mathrm{O}_{4}$ Ball-in-Ball Hollow Microspheres as a High-Performance Anode for Lithium-ion Batteries, Adv. Mater., 2012, 24, 4609-4613.

22 X. Wang, C. Yan, A. Sumboja and P. S. Lee, High Performance Porous Nickel Cobalt Oxide Nanowires for Asymmetric Supercapacitor, Nano Energy, 2014, 3, 119-126.

23 J. Zhang, J. P. Cheng, M. Li, L. Liu, F. Liu and X. B. Zhang, Flower-Like Nickel-Cobalt Binary Hydroxides with High Specific Capacitance: Tuning the Composition and Asymmetric Capacitor Application, J. Electroanal. Chem., 2015, 743, 38-45.

24 U. M. Patil, J. S. Sohn, S. B. Kulkarni, S. C. Lee, H. G. Park, K. V. Gurav, J. H. Kim and S. C. Jun, Enhanced Supercapacitive Performance of Chemically Grown CobaltNickel Hydroxides on Three-Dimensional Graphene Foam Electrodes, ACS Appl. Mater. Interfaces, 2014, 6, 2450-2458.

$25 \mathrm{~L} . \mathrm{Hu}, \mathrm{L} . \mathrm{Wu}, \mathrm{M}$. Liao, X. Hu and X. Fang, Electrical Transport Properties of Large, Individual $\mathrm{NiCo}_{2} \mathrm{O}_{4}$ Nanoplates, Adv. Funct. Mater., 2012, 22, 998-1004.

26 C. Tang, Z. Tang and H. Gong, Hierarchically Porous Ni-Co Oxide for High Reversibility Asymmetric Full-Cell Supercapacitors, J. Electrochem. Soc., 2012, 159, A651-A656. 
27 G. Hu, C. Tang, C. Li, H. Li, Y. Wang and H. Gong, The SolGel-Derived Nickel-Cobalt Oxides with High Supercapacitor Performances, J. Electrochem. Soc., 2011, 158, A695-A699.

28 R. Wang and X. Yan, Superior Asymmetric Supercapacitor Based on Ni-Co Oxide Nanosheets and Carbon Nanorods, Sci. Rep., 2014, 4, 3712.

29 B. Sarma, R. S. Ray, S. K. Mohanty and M. Misra, Synergistic Enhancement in the Capacitance of Nickel and Cobalt Based Mixed Oxide Supercapacitor Prepared by Electrodeposition, Appl. Surf. Sci., 2014, 300, 29-36.

30 L. Shen, Q. Che, H. Li and X. Zhang, Mesoporous $\mathrm{NiCo}_{2} \mathrm{O}_{4}$ Nanowire Arrays Grown on Carbon Textiles as Binder-Free Flexible Electrodes for Energy Storage", Adv. Funct. Mater., 2014, 24, 2630-2637.

$31 \mathrm{H}$. B. Wu, H. Pang and X. W. Lou, Facile Synthesis of Mesoporous $\mathrm{Ni}_{0.3} \mathrm{Co}_{2.7} \mathrm{O}_{4}$ Hierarchical Structures for HighPerformance Supercapacitors, Energy Environ. Sci., 2013, 6, 3619-3626.

32 U. S. Mohanty, Electrodeposition: a versatile and inexpensive tool for the synthesis of nanoparticles, nanorods, nanowires, and nanoclusters of metals, J. Appl. Electrochem., 2011, 41, 257-270.

33 J. Zhu, J. Jiang, Z. Sun, J. Luo, Z. Fan, X. Huang, H. Zhang and T. Yu, 3D Carbon/Cobalt-Nickel Mixed-Oxide Hybrid Nanostructured Arrays for Asymmetric Supercapacitors, Small, 2014, 10, 2937-2945.

34 J. R. S. Brownson and C. L. Clément, Electrodeposition of $\alpha-$ and $\beta$-cobalt hydroxide thin films via dilute nitrate solution reduction, Phys. Status Solidi, 2008, 245, 1785-1791.

35 Z. Wu, L. Li, J.-M. Yan and X. Zhang, Materials Design and System Construction for Conventional and New Concept Supercapacitors, Adv. Sci., 2017, 4, 1600382.

36 G. Aranovich and M. Donohue, Analysis of adsorption isotherms: lattice theory predictions, classifications of isotherms for gas-solid equilibria, and similarities in gas and liquid adsorption behaviour, J. Colloid Interface Sci., 1998, 200, 273-290.

37 M. J. Barmi and M. Minakshi, Tuning the redox properties of the nanostructured $\mathrm{CoMoO}_{4}$ electrode: effects of surfactant content and synthesis temperature, ChemPlusChem, 2016, 9, 964-977.

38 T. Watcharatharapong, M. Minakshi, S. Chakraborty, D. Li, G. M. Shafiullah, R. D. Aughterson and R. Ahuja, Effect of transition metal cations on stability enhancement for molybdate-based hybrid supercapacitor, ACS Appl. Mater. Interfaces, 2017, 9, 17977-17991.

39 H. Liu, P. He, Z. Li, Y. Liu and J. Li, A novel nickel-based mixed rare-earth oxide/activated carbon supercapacitor using room temperature ionic liquid electrolyte, Electrochim. Acta, 2006, 51, 1925-1931.

40 W. Liu, X. Li, M. Zhu and X. He, High-performance all-solid state asymmetric supercapacitor based on $\mathrm{Co3O} 4$ nanowires and carbon aerogel, J. Power Sources, 2015, 282, 179-186.

41 M. J. Barmi and M. Minakshi, Role of polymeric surfactant in the synthesis of cobalt molybdate nanospheres for hybrid capacitor applications, $R S C A d v ., 2016,6,36152-36162$.

42 T. Chen, R. Shi, Y. Zhang and Z. Wang, A $\mathrm{MnCo}_{2} \mathrm{O}_{4} @ \mathrm{NiMoO}_{4}$ Core-Shell Composite Supported on Nickel Foam as a Supercapacitor Electrode for Energy Storage, ChemPlusChem, 2019, 84, 69-77.

43 Y.-Y. Huang and L.-Y. Lin, Synthesis of ternary metal oxides for battery-supercapacitor devices: influences of metal species on redox reaction and electrical conductivity, $A d v$. Energy Mater., 2018, 1, 2979-2990.

44 S.-B. Yoon, J.-P. Jegal, K. C. Roh and K.-B. Kim, Electrochemical impedance spectroscopic investigation of sodium ion diffusion in $\mathrm{MnO}_{2}$ using a constant phase element active in desired frequency ranges, J. Electrochem. Soc., 2014, 161, H207-H213. 